\title{
ICT (Information and Communications Technology) Value in Korean Education: Technology and Pedagogy ${ }^{*}$
}

\author{
Chun Seyeoung \\ Chungnam National University, \\ Daejeon, South Korea
}

\author{
Kye Bokyung \\ Korea Education and Research Information Service, \\ Seoul, South Korea
}

\begin{abstract}
This study aimed to look back upon the two decades of ICT (information and communications technology) in education and to examine its merits and demerits, and thereby evaluating the value of ICT in educational development from the viewpoints of Korea and the world and finding lessons to take a leap toward further advancement. To this end, we researchers examined the process of ICT in education, from making policies based on Korea's socio-cultural contexts to implementing the policies at school levels. Through descriptive study, we also identified best practices and success factors for ICT integration and discussed their implications. The study revealed four lessons for policy leadership as a success factor, school ecology as a complex factor, the gap between technological and social development as a crisis factor, and the task of pedagogy as a fundamental assignment. The implications of the study give insight into realizing a long-cherished wish for the education for all. The task of traditional pedagogy is passed over to the task of a new one which Korean experience of ICT education proposes.
\end{abstract}

Keywords: ICT (information and communications technology) in education, smart education, technology, pedagogy, South Korea, EFA (Education For All)

\section{Introduction}

South Korea (hereinafter referred to as "Korea") is widely recognized for its remarkable growth even after the devastation of the Korean War. No one can disagree that educational development was Korea's first achievement as a part of the economic and social development miracle that took a mere half of a century, the shortest period in human history, from the ruins of Japanese occupation and inter-Korean division. Ever since the OECD (Organization for Economic Co-operation and Development) published EAG (Education at a Glance) in 1995, Korea has vied with Finland for the highest rank in the PISA (Programme for International Student Assessment) assessment. Although there is room for disagreement in terms of interpretation, Korea's college entrance rate has already exceeded $80 \%$ and Korea has become the world's first nation to approach "Higher Education for All”. ICT (information and communications technology) has been an essential factor in the success of Korea's educational development process and has especially been a driving force for the educational revolution to move toward an information and knowledge-based society of the 21st century (Ministry of

\footnotetext{
* This paper is prepared for presenting to the 2014 CIES conference in Toronto based on the original research report which was funded by a grant from Intel ${ }^{\circledR}$ and conducted by its EDC research guidelines and survey tool. The data presented, and the statements made and the views expressed are solely the responsibility of the authors.

Chun Seyeoung, Professor, Department of Education, Chungnam National University.

Kye Bokyung, Senior Fellow, Smart Education R \& D Division, Korea Education and Research Information Service.
} 
Education \& Korea Education and Research Information Service, 2013).

According to the 2009 PISA assessment scores, South Korea ranked at the top of the digital reading assessments among the 19 participating OECD countries. First introduced in 2009, the digital reading assessment has been used to measure reading ability within a digital media environment, an essential skill required in the 21st century. This evaluation aims to measure thinking ability, creativity when collecting information through hyperlinks, and ability to apply and comprehend various types of information that exist in various forms on the Internet. These skills are difficult to measure through print media. In this assessment, Korea recorded an unrivaled achievement with 69 points higher than the average OECD score and 31 points higher than New Zealand, the second highest ranked country. Korea also displayed the smallest difference in scores between the highest and lowest scores in digital education assessments (Song, Rim, Choi, Park, \& Son, 2013). This implies that Korean children are prepared to live in the digital era and that ICT in education for Korea has not worked to worsen the digital divide but to resolve the divide.

Similar to the education problems that countries around the world have encountered, Korea has also faced limitations in promoting skills needed in the 21st century for learners with traditional forms of classroom and textbook-delivered knowledge. Furthermore, an education system centered on academic assessments and test performance has hindered the social and technological changes in learning. As a result, we have failed to provide satisfactory education for students performing above and below average. Due to these complicated factors, there is a growing demand for change in our education system. Consequently, educating the new generation has become an urgent issue for the nation in order to keep up with the knowledge revolution that is rapidly changing in the 21st century. It is no exaggeration that a nation's destiny depends on the potential of its young generation and that this change is crucial in the 21st century when an educated imagination makes up a creative nation.

In this respect, this study aimed to look back upon two decades of ICT in education and to examine its merits and demerits, thereby evaluating the value of ICT in educational development from the viewpoints of Korea and the world as well and finding lessons to take a leap towards further advancement. To this end, the study looked into the process of ICT in education from making policies based on Korea's socio-cultural contexts to implementing these strategies at school levels. Through in-depth studies, it also identified best practices and success factors for ICT integration and discussed its implications.

\section{Research Method}

This study collected policy context memos, and conducted a school survey and school investigation in the last fieldwork phase. For the analysis of policy contexts, researchers interviewed three experts from the Ministry of Education and the institute dedicated to the ICT use in education, who played an essential role in the policy-making process, and five superintendents from provincial and municipal offices of education, which actually implement the ICT policy. The study also made a literature review of related materials, policy documents, and press releases.

For a school-level survey, we selected five excellent schools from smart education experiment schools and conducted a questionnaire survey and interview of about 30 principals, executive teachers, ICT teachers, and general teachers. We also collected and analyzed reports, class videos, and related materials produced from experiment schools. For school-level observations, we performed a case study of the two leading schools in implementing smart education, observed class lessons, and conducted an in-depth interview of teachers, 
students, and parents. For an overall analytic frame of the study, we selectively used "Intel Guide to Monitoring eLearning Program” in accordance with Korean contexts and situations.

Table 1

Subject Schools

\begin{tabular}{|c|c|c|c|c|}
\hline \multirow{2}{*}{ STEP } & \multirow{2}{*}{ School name } & \multirow{2}{*}{ School level } & \multicolumn{2}{|l|}{ School features } \\
\hline & & & Public/Private & Region \\
\hline \multirow{7}{*}{ School Survey } & \begin{tabular}{|l} 
Gwanpyeong \\
Elementary
\end{tabular} & Primary school & Public & Medium and small city \\
\hline & \begin{tabular}{|l|} 
Sinpyeong \\
Elementary \\
\end{tabular} & Primary & Public & Medium and small city \\
\hline & Sunrin Internet High & High school & Public & Metropolitan city \\
\hline & \begin{tabular}{|l} 
Sinil Girls’ High \\
\end{tabular} & High school & Public & Medium and small city \\
\hline & Imun High & High school & Public & Medium and small city \\
\hline & Itaewon Elementary & Primary school & Public & Metropolitan city \\
\hline & \begin{tabular}{|l|}
$\begin{array}{l}\text { Geumgwang } \\
\text { Elementary }\end{array}$ \\
\end{tabular} & Primary school & Public & County and village \\
\hline \multirow{2}{*}{$\begin{array}{l}\text { School } \\
\text { Investigation }\end{array}$} & \begin{tabular}{|l|} 
Gyeseong \\
Elementary
\end{tabular} & Primary school & Private & Metropolitan city \\
\hline & \begin{tabular}{|l|} 
Chamsaem \\
Elementary
\end{tabular} & Primary school & Public & Medium and small city \\
\hline
\end{tabular}

For an overall analytic frame of the study, we selectively used "Intel Guide to Monitoring e-Learning Program" in accordance with Korean.

\section{Policy Context: Korea's Current Implementation of Policy on the ICT in Education}

The policy to integrate technology into education in South Korea (hereinafter referred to as "Korea") aimed at improving public education, at promoting economic growth, and at extending ICT accessibility. Korea has established master plans for the use of ICT in education policy on three phases to innovate education system since 1996. The first phase was about the foundation construction (1996 to 2000), the second phase was about proliferation and settlement (2001 to 2005), and the third and fourth phase(s) was about acceleration (since 2006). In particular, Korea has established a new plan to improve education and science in the nation's HRD (Human Resources Development) in the fourth phase (2011-2015), and we have focused on not hardware-based information but soft power of information. We have tried to find solutions for the information not inherent in education and learning through the learning ecosystem. Similarly, a SMART Education has been initiated as an educational information policy that pushes ahead with the plans of the phase IV. One of the most critical strategies for integrating the use of ICT into education has been to implement SMART Education (2011-2015). The goals of this new strategy are clearly displayed in the title: SMART Education stands for Self-directed, Motivated, Adaptive, Resource enriched, and Technology embedded. By using ICT in the framework of education, science, and technology, SMART Education Initiative aims to promote plans to enhance the agenda of schools and educational policies.

SMART Education is the first policy to attempt to overcome the limitations of existing ICT use in education. Since it is a policy to integrate ICT institutionally and culturally into education and curriculum, SMART Education promotes the use of ICT as a primary source of learning, rather than a supplementary resource. Above all, SMART Education offers an education that enables learning through a teaching and learning system tailored to the needs of each individual student at any time and at any place. Through SMART 
Education Initiatives, the previous emphasis on the 3R's (Reading, aRithmetic, wRiting) will shift the focus in education to the system more suitable to the 21st century learner; we now enter a world that demands the 7Cs (Critical thinking and problem-solving, Creativity and innovation, Collaboration and leadership, Cross-cultural understanding, Communication, ICT literacy, Career and life skills).

The strategy for implementing SMART Education is largely composed of five key tasks: (1) Development and application of digital textbooks which overcome limits of printed textbooks, improve teaching at classroom, and implement customized learning; (2) Institutionalization of online classes (which are admitted as regular classes) and introduction of online evaluation systems to guarantee learning options; (3) Creation of an environment for the public use of educational content and reinforcement of information and communications ethics education to resolve adverse effects; (4) Strengthening of teachers' competencies to put SMART Education into practice; and (5) Practical use of the contents created by public agencies and individuals through a cloud computing-based environment in every school, and public use of learning resources and establishment of collaborative learning environments through collective intelligence and social learning (Council on Informatization Strategies \& Ministry of Education, Science and Technology, 2011).

As a strategy for implementing the five key tasks, first of all, the relevant laws and systems to allow for changes in educational paradigm have been called for action. By extending the scope of learning from the educational place called "school" to any place-including homes and hospitals where learning happens-education can take place anywhere and at any time. Some options have been proposed to achieve these objectives; they are to use actively online classes, provide rich teaching and learning materials, and acknowledge online classes as equivalent to regular class hours, and be able to make free use of educational materials in class. The second, task is to establish a virtuous cycle system that comprises of educational system, participants, teaching and learning methods, and educational environment. Although so many elements are involved in education, it is the most important one to enable individualized and customized learning through an accurate diagnosis of students' levels and prescription of suitable lessons based on individual student's level. Therefore, SMART education policy is strongly targeting to build necessary assessment systems and strengthen teachers' competencies as well. The third one is to eliminate information gaps and minimize malfunctions that may arise in the SMART Education environment. Applying SMART Education must take a keen consideration to the less privileged sectors of society in education, including low-income and multicultural families, and minimize the possible educational gap that may occur within the SMART Education environment. To prevent adverse effects such as Internet or game addition, which may happen as learners are more exposed to ICT, SMART Education policy is designed to cover the related issues by utilizing necessary information about these problems and the prescriptions. The last task is focused on taking a care and prudence when introducing rapidly changing information technology to classrooms. Through practicing and researching by operating at pilot schools and phased expansion, the burden of SMART Education must be reduced, together with promoting societal understanding and positive perception of SMART Education through a public campaign. The promotion can be achieved by establishing and operating future education research centers equipped with theoretical research and on-site consulting functions.

However, an increasing number of voices are calling for the full implementation of SMART Education delayed until scientific verification of its effectiveness and digital devices' impacts on health concerns such as eyesight, mental health, and so on. And most teachers are insisting that they need some time before they are required to apply it into classes. Given the current situation, it is necessary to gradually implement the policy 
based on the conditions and opinions of schools, instead of rushing into the policy. Moreover, infrastructure needs, like supplying smart-devices and wireless-internet, costs a lot, and the voices of dissents about supply business of major companies are growing louder. If there were a time when the ability of government as a mediator to enhance policies by mediating interests of various subjects and leading them to the desired direction, were necessary, it is now more than ever.

\section{Case Studies}

\section{School-Level Implementation}

The following are the results of the survey conducted to examine the combination and implementation of technologies at school levels from the aspects of accessibility to technology, teacher's professional development and support for ICT use, teachers' readiness for technology, and leadership and school culture.

\section{Accessibility to Technology}

Schools make primary investments on changing the existing wired-internet to a wireless-internet environment and introducing smart-devices. Building a wireless-internet environment is one of the most difficult issues at schools, where they build a wireless-internet environment in the method of installing one or two APs (access point(s), which is a device for wireless internet access like Wi-Fi) per classroom. Although it is difficult to introduce the wireless-internet, class lessons are often delayed or cannot be proceeded as planned, because stable connection to the wireless-internet is not guaranteed. This is one of the elements which schools find difficult with a wireless-internet environment (Kye, Lee, Kim, Park, \& Lee, 2013).

To provide personal device to an individual student, a majority of schools planned to introduce smart-devices in addition to general PC (personal computers) which had already been introduced and constantly distributed through the existing ICT applied classroom project. A higher proportion of schools introduced Android-based smart-devices. It seemed that schools selected these devices thinking it is more desirable to introduce domestic products (made by "S" company) if their functions are almost identical, given the feature of schools that they are public institutions. Methods for using smart-devices were determined by the school's budget size for introducing the devices. Methods for distributing the devices included "one-on-one device" method (i.e., Chamsaem, Geumgwang, Gyeseong Elementary Schools) and "one device per group” method. Furthermore, a model of "purchasing smart-devices for a class and jointly using them" (i.e., Itaewon Elementary School) became common. A model of using common devices was mostly adopted when schools intended to give opportunities for more students to use smart devices with relatively low budget. In this case, smart-devices storage boxes were separately installed and managed at a common space in school. In other cases, schools made a cart for joint use equipped with both functions of storage and recharge boxes.

Some schools such as Chamsaem Elementary School introduced and used other devices including electronic whiteboards and digital teaching platforms. There are a higher proportion of general classrooms using smart-devices in connection with a projection TV or a projector, which had been distributed into classrooms through the IPTV distribution project. It also showed that a higher proportion of classrooms introducing electronic whiteboards and digital teaching platforms to an auditorium or special lecture room and jointly using them.

In terms of the software, there has been emerged a classroom-level solution market since the introduction of SMART Education policy so that teachers can operate all devices at classrooms under their control. Some 
schools introduced such solutions at the school level (i.e., Gyeseong, Itaewon, and Chamsaem). Although it took a considerable time to learn solutions whose main functions include students' smart-device and screen control and data sharing between a teacher and students and between students, schools recognized them as basic solutions for SMART Education. In a case, teachers used Apple TV or Samsung mirroring equipment to perform lessons. This case attracted attention from teachers as a simpler model, which enables them to operate diverse class models without being restricted by the blackboard. In addition, there was an increasing proportion of classes using cloud computing-based software such as Google Docs or "Classting” a class-level community support application made by a teacher, was also used by a number of teachers. Teachers who searched for smart-device applications that are useful for their subject lessons and class operation introduced them via Facebook (a social networking site). They were also actively engaged in sharing activity with other teachers in the same interests. Teachers utilized and introduced largely general-purpose tools that were easily purchasable on the Internet according to their needs. Most learning support tools were free or low-priced and they were purchased at the personal cost of teachers or in some cases were paid back by schools in the form of gift certificates after their purchase, because there were no clear guidelines. From this, it is assumed that the introduction of new technology is not yet connected to the institutions or systems at schools. Besides the contents for lesson materials according to teacher's lesson plans and learning scenarios, there was a deviation in the frequency of using software in class lesson. However, it was found that teachers often used software related to document editing, search and cloud computing. Also, with the introduction of smart-devices, the use of tools connected with mobile mirroring and cloud computing was remarkably increasing.

\section{Teachers' Professional Development and Support for ICT Use}

In implementing Korea's ICT use in education, teacher training has always been one of the most important issues(Chun et al., 2013). Teacher training has systematically taken root at school levels, and a structured training system is still validly existed in the form of which leading teachers are trained at the central level, and these leading teachers conduct transfer training for general teachers at regional levels. As offline training programs and online programs are separately offered for general teachers at provincial and municipal offices of education, teachers who want to receive training can apply for and participate in training individually through provincial and municipal offices of education under the approval of their principal. In addition to the training at the central or provincial and municipal levels, schools conduct self-training about the contents necessary for the school or encourage participation by supporting group activity or subject study activity at schools. In the case of teachers who are interested in technology but do not have much career experience, they actively participated in training as they had incentives of getting training points useful for promotion or of nurturing their competency to catch the opportunity to work as leading teachers. In particular, teachers who first adopted technology and had experience of using technology, in many cases, became "star teachers" in the related field by having opportunities for participating in the government- or private business-led ICT projects in education or widely spreading their experience using SNS (Social Network Service). This had a positive effect on creating and spreading a model case of bottom-up approaches, in which teacher groups take the initiative in complying with the government policy. However, it is also pointed out that these groups may end up exchanging only inside their group of avid technology users according to their own needs without bringing the effect on proliferating innovation through technology in the school fields.

As more duties on operation and management of technology were gradually added to schools, a growing 
number of schools employed computing assistants. This trend gained a good response from teachers because the assistants reduced their burdens and time to prepare technology all alone as well as relieving them of the burdens on handling IT-related miscellaneous affairs at schools. Due to limited budget, however, most schools could not hire computing assistants.

\section{Teacher's Readiness for Technology}

To be selected for a pilot school, members should form a consensus on the issue in advance because there is a mandatory clause in the selection procedure of a pilot school that requires consents from all teachers. In the case of Itaewon elementary school, a pilot school for the SMART Education, its principal first asked opinions to teachers according to the procedure and persuaded them to consent. In the case of Chamsaem elementary school, its members were voluntarily participating in SMART Education project, as the school had already been designated as a SMART school from the beginning of its establishment. The school recruited teachers through a process in which teachers who were interested in SMART Education volunteered to work at the school and then they were allocated to the school. Depending on schools, SMART Education was introduced by teachers' personal interests and autonomously implemented in many cases.

In general schools, teachers from aged groups resisted to the mandatory introduction of technology, clung to conventional teaching and learning methods, or indifferent to the technology introduction. However, as a majority of teachers had to accept technology as requirement for various reasons, they played a leading role in introducing technology. For teachers in pilot schools for the ICT use or for a majority of teachers in general schools who are not resistant to the ICT use, what is most needed is practicing effective lesson models using ICT rather than learning the skills for using ICT itself. Because the primary environment for using ICT has been built regardless of the high or low level of technology, we are now in a stage to mull over new ideas and desirable directions for operating classes in reality.

\section{Leadership and School Culture}

The case that the principal among the pilot schools surveyed showed the most outstanding leadership was Itaewon Elementary School. In the case of Itaewon Elementary School, a new principal was selected by public competition and took office. The principal then invited teachers who shared the same goal and vision with him through teacher invitation system. This triggered changes in the school. Since its foundation, this school had not introduced any technology nor had any history of doing an external activity including selection for pilot schools. With the inauguration of the new principal, however, the school applied for SMART Education pilot school designated by the Seoul Metropolitan Office of Education in an effort to promote a new investment, which could bring changes to the school. With the persuasion of the principal and teachers who approved introduction of technology, teachers who were against or hesitant to the application of a pilot school at the beginning gave consents and the school could gain more than $80 \%$ consents from its teachers, which was required for the application. The school then began to be engaged in SMART Education pilot school activity and is actively sharing its experience of introducing ICT with other schools at the current stage.

On the other hand, Gyeseong Elementary School, a private school, is a case in which teachers, not the principal, introduced ICT. Led by teachers, SMART Education was first introduced at class level and then it was gradually expanded school-wide. In this case, the principal entrusted authority over deciding the directions for introducing and operating the technology to head teachers and teachers at large and played the role of encouraging the teachers, while head teachers exercised the authority over introducing ICT. 
In the case of general pilot schools, a group centering mostly on the IT leading teacher and triggered by designation of a pilot school played a leading role in making plans for the ICT operation at school and teachers simply participated in the process. In the case of Sunrin Internet High School, with the change in school name to Internet High School, the principal, head teachers, and teacher group divided their roles properly with a goal to share visions with each other and introduce ICT. They have constantly developed and efficiently operated the school according to school situation. The efforts of these schools were all made under the guidance and support of provincial and municipal offices of education. In this process, positive interaction with the provincial and municipal offices was made in the order of pilot schools, general public schools, and private schools.

Although lessons are given in a big frame of national curriculum and school's curricular operation plan, teachers have full authority over lesson design or operation. If finance is required for introducing something new including ICT to class, teachers should get approval for the use of budget in consultation with the principal and head teacher in charge. However, teachers have full discretionary power when attempting to introduce a new method of lesson to class.

\section{Class-Level Implementation}

The following are the results of a case study conducted to examine from in-depth perspectives the combination of ICT with curriculum, class, and assessment at classroom levels and the connection of ICT with the local community and schools.

\section{Contexts of Typical Classrooms}

In a typical class at general schools, technology is generally used in the manner of employing multimedia as supplementary materials via IPTV, projection TV, or beam projectors which were distributed through the ICT-applied classroom project, while teacher-centered instructions are largely composed of classes based on textbooks as main teaching material. If teachers continue to show them passive materials without activities, students will become soon bored and teacher's voice alone will fill the classroom. Teachers may sometimes raise a question to check if students understood but the teacher does not expect any answer from students because of limited class time. Unlike elementary schools where group learning activity is offered at times, this situation worsens in secondary schools under the big influence of school system emphasizing on college entrance examination, for which the teacher keeps on teaching the subjects and having students take examination. There is almost no change in the linear arrangement of seats for lecture-style class and students have to sit on the fixed seat and listen to the instruction unless there are special reasons.

\section{Contexts of Innovative Classrooms}

On the other hand, in innovative classes, technology is not used as a supplementary medium to show learning materials on the screen instead of on the blackboard or hanging maps used in the teacher-centered instruction. Technology functions as an essential learning tool for students to lead their learning for themselves. The cases of the class in Chamsaem and Gyeseong elementary schools illustrate these elements.

Scientific exploration class at Chamsaem Elementary School. Chamsaem School conducted an explorative learning activity class utilizing its own diverse learning spaces. The school suggested the missions that students apply scientific exploration activity models and activity strategies, and then had students selectively perform three to four linked activities after resolving each mission. The problems in the mission were to explore scientific principles about objects, material, plants and minerals and designed to help students 
learn and explore subject contents in a natural way in the process of collecting evidence in the search of answers inside the school using the smart-devices.

In addition, to give students a goal for performing the mission and instill a sense of accomplishment of the mission, the teacher provided a story of "Adventure of Prince Philip" so that students can carry out four missions consecutively beginning with the story. The teacher provided clues for students with QR (Quick Response) codes (QR code is the trademark for a type of matrix barcode) containing multimedia-type material and deployed them here and there at school. While searching for clues, students inferred and looked for answers about the objects, materials, plants, and minerals based on the features as suggested in the mission. After resolving the mission, students were able to have enriched learning activities through a comparison of similarities and differences, and connected activities of making scenarios and videos.

The effect of this class could be found from the following statements made by students (Lee, Gu, Shin, Kim, Kye, \& Jung, 2012);

First, this class contributed to raising the spirit of inquiry about scientific knowledge, arousing curiosity about learning content, and drawing various ideas.

Student 1: "When I saw the clue, I was curious and inquisitive about what would come out".

Student 2: "It was interesting when we had different ideas while seeing the same clue".

Second, the class contributed to helping students to take greater interests in class and have a sense of goal through the suggestion of explorative activity in the form of mission.

Student 1: "It was very difficult to find the similarities and differences between the answers and make up a story".

Student 2: "Still, it was interesting to solve the challenging problem".

Third, this class was successful in having students feel both difficulty and joy together through the competition between groups and cooperation within the group, coordinate conflicts and opinions with each other, and feel a sense of fulfillment and confidence.

Student 1: "We got along well with each other but as we had different ideas, we argued and fretted. However, as we solved problems one by one, we came to be more attentive to other's opinion”.

Student 2: "It was good to foster teamwork and collaboration through the accomplishment of the mission. I had also a good time experiencing many things with friends while carrying out the mission and got to understand their character as well”.

In addition, students could overcome the fixed idea about the ICT use in general schools that it is to sit in their own seat and rivet their eyes on each smart-device. On the contrary, they walked about their school area to collect evidence about the answer to the problem suggested in the mission and took a video for role-play. As a result, their physical activity was facilitated and improved in a natural way.

Student 1: "It was greatest fund to move about outside the classroom to carry out the mission, because we did not usually go out during class hours. It was interesting to walk about to do the outdoor activity".

Student 2: "The most interesting thing was to walk about every corner of the school with friends to solve the problem. I came to know better about things in my school and its geography through this project”.

Because of the special learning environment of Chamsaem School where devices are basically distributed to students on a 1 to 1 basis, students used the device in some cases to do other activities, like games or search, than to do scientific exploration activity while carrying about several devices for their activity. It is notable, 
however, that students suggested the following opinion for themselves to improve the class next time.

Student: "Because we can do other things when we use our pads individually, it would be good to let us use only a smart-device among group members to stave off temptation to be engaged in other activities”.

In addition to this, the teacher took a follow-up measure to ensure sharing study results and exchanging feedbacks with each other so that students might not merely do the activity, but summarize their learning completely.

Teacher: "Students were happily engaged in class thanks to interesting photos of proof. I asked them to edit their photos of proving their mission accomplished and upload them on Classting. This allowed all students to see the photos together. I also let any group of students who had already solved their problems see other work of their friends and leave comments on the work. It helped their character-building education”.

Physical education class at Gyeseong Elementary School. Every student of the Grade 4 "Tender" Class at Gyeseong Elementary School in Seoul, held a smart pad in their hands when they went out to the school's grassy, sports field for their physical education class. The students warmed up with basic stretches and then proceeded to use their smart pads. Their activity for the class was Frisbee, a game where students toss around a flying disc to one another. The students paired up into groups of two consisting of one boy and one girl to face each other while playing. First, the boy or girl student threw a Frisbee while his or her partner filmed. Then, the student who recorded the exercise replayed the movement and then threw the Frisbee him or herself. The students continued to alternate roles of throwing the Frisbee or recording the exercise on the smart pad.

The Grade 4 "Tender" Class has been designated as a pilot class for the smart school. In the mornings, the homeroom teacher instructed the students to $\log$ in when they first entered the classroom. He then announced that class had begun and students immediately pushed the attendance button on their smart device. Once they pressed the button, a yellow light appeared on the whiteboard, thus performing the "digital attendance check". Yellow lights from 30 personal computers showed that all students were present on the teacher's whiteboard count. The teacher then said, "Let's see how your posture has changed through the video you took on the sports ground just a few moments ago".

The teacher and students' smart devices were linked to one another creating a solution for interactive class involvement. The teacher's smart device could remotely control students' PCs, share files with one another, and conduct a quiz, questionnaire, survey, vote, as well as an assessment. The students' smart devices were filled with digital textbooks for different subjects and contained multimedia lesson materials. They had already shared a video titled, "The Proper Posture of Flying Discs”, before they attended the physical education class. When they compared the originally shared video with their own self-recorded videos taken during the class, they could see instantly where to correct their own Frisbee postures. The teacher sent his students an instant online questionnaire titled, "Thoughts About the Posture of Flying Discs". He then asked them to answer the question, "Do you think you had a proper posture of flying disc?” with the response of yes or no. Twenty-seven students responded with yes. A graph about the questionnaire then appeared on the whiteboard. Students typed in their evaluations of their posture with opinions such as, "I should have placed the Frisbee horizontally" or, "I will have better balance next time”. In only two minutes, the thoughts of each student appeared on the whiteboard in a clear table format. All of the students were able to express their opinions freely while communicating with one another in real time. 
Student 1: "The video showed me that I raised my arm slightly higher when throwing the flying disc. It was helpful in correcting my posture for myself”.

Student 2: "Since my favorite smart devices are used in class instead of books, I can concentrate better and the class is more fun. It is also good to take pictures of my friends' movements and learn the exact movements at the same time".

When the bell rang to end the class, the teacher automatically turned off students' PCs through the online network. The use of PC must be complied with the teacher's strict control. Students inserted their smart devices in the large recharger beside the whiteboard in an orderly manner.

\section{Integration of ICT With Curriculum, Class, Assessment, and Technology}

Integration of ICT in classrooms has largely been made in the method of displaying various kinds of multimedia materials using ICT devices. Only the media have changed from writing texts or drawing pictures on the blackboard or showing hanging maps/charts to displaying PPT or video materials on the projection TV/on the beam projector. It seems to be a desired, but yet challenging task for teachers to use ICT in school, promoting communication and interaction between teacher and student, between students, at both school and home; emphasizing students' active engagement and initiative in their learning. In fact, integration of ICT in classrooms might contend for change in teaching and learning paradigm. It is still pointed out, however, that such technology with an emphasis on ideal interaction in education is usually distributed with insufficient technical features or inconvenience to be used; that newly distributed technologies do not have enough contents suitable for them; that the technology is in a situation where it cannot be actually used; and there is a gap between educational system and evaluation system.

Nevertheless, one of the significant changes from the implementation of SMART Education policy in school is that teachers began to set a learning goal for strengthening students' competencies of the 21st century and apply the goal to the class lessons as a meaningful activity. Previously, they had set a goal for educational process which resulted in the existing measurement of academic performance. This change is significant even if the term "competency of the 21st century" still seems "words without substance" and technology is not so easy to use for teachers and students. Also, some teachers directly experienced the effect of using ICT. For example, an art teacher changed her teaching methods from showing students materials prepared beforehand by herself to asking students to use their smart-devices. She said, "If I gave students time to search a related material in class hours, they could view and share 25 examples instantly, and sought more diverse ways of expression" and "I had students make peer assessment items using Google Form and directly evaluate the presentation of their classmates. As a result, they paid more attention to the group presentation of other groups and could receive feedback in real time".

In this process, teachers reflected on their class and made improvements of the class. For example, they found some problems that students made emotional assessment of the presentation of other groups without giving much thought about the simple question over whether they made a good presentation or not, because they were unfamiliar with the assessment. Students gave a favorable point if their friends made a presentation or if the presenter had a loud and clear voice regardless of the content of presentation. To solve these problems, teachers began to think over how to suggest specific assessment questions, like "Was cold feeling expressed well?” instead of general questions, like "which group did a good job?”. They are now no longer much concerned about which technology they will use in class. Rather than considering which tool they will use in each session, teachers began to spend more time developing appropriate indicators for assessment. In this process, technology is genuinely integrated with learning content or assessment so that technology becomes no 
longer something new. We could also find a few cases of positive ICT use in which teachers took photos of all kinds of learning outcomes including students' three-dimensional outcomes, turned them into portfolios and managed them by grade and by theme. Or using assessment support application for teachers such as Teacher-Kit, they entered evaluation results and gave feedback in real time. In this way they could improve the situation in which they had a hard time providing individual prescriptions for many students while there was only one teacher.

Also, various tools such as questionnaire tools and e-Clicker were often used in assessment. These tools were assessed as easy and effective models of ICT use, in which they enabled teachers to make instantaneous interaction, such as checking learning situations and understanding of students in real time and giving supplementary explanation about insufficiently understood areas.

\section{Connection Between the Local Community and Classes}

In other cases, teachers gave students new motivation about learning or provided opportunities for them to sincerely ponder about their future career for themselves by linking celebrities or experts on the video conferences in connection with the talent donation movement implemented by the government. They often offered classes that are designed to have students feel actual fields more vividly in connection with science hall or companies. The limitations of ICT use, however, is that the connection to the video conference does not still go smoothly; that a process to connect to the video conferencing system is so complicated that only particular teachers with a lot of training and experience can attempt at this type of class; and that even these teachers regard such class as troublesome or burdensome.

In addition to direct teaching and teaching scenes, it has been found that there are positive impacts on promoting communication with parents and students by using ICT through communication from the aspect of out-of-class. Introduction of ICT enabled teachers to inform their parents of students' attendance in real time on the smart-phone or of home correspondences and to send pictures taken from school trip by email or on the class community. In this regard, the use of ICT noticeably raised parents' satisfaction with schools. This effect of communication were of great help to teachers in understanding and guiding individual students, but there were also unexpected happenings as well.

For a clear example, Chamsaem School had to experience a happening of overly crowded class. Because the school was designated from the start of establishment as SMART Education pilot school, many parents tried to transfer their children to this school. As a consequence, the school has raised the fixed number of students per a class from 25 to 30 since its opening in 2012 and increased the number of classes even during school terms. In Korea's public elementary schools, students are allocated to a nearest school according to the area where they reside. In this turmoil, the local parent community reported falsely transferred students to the education office and searched out these students. Even the education office conducted visit surveys of the suspected households to check if they actually resided in the area.

It is definitely positive that there are active communication channels where teachers, students, and parents can share class news or information and exchange opinions with each other. As a result, the communication channels always exist between teachers and parents, and communication between students and teachers can be promoted. However, we also need to pay attention to the fact that teachers' burden of their duties also becomes heavier even during out-of-class hours. Teachers then need to make greater efforts to use these channels effectively as useful educational tools for communication with students. 


\section{Research Findings}

Korea's ICT in education has been effectively implemented for a total of 15 years in three phases from the first phase in 1995 to the announcement of SMART Education Initiative on June 29, 2011. This study revealed four lessons about policy leadership as a success factor, school ecology as a complex factor, the gap between technological and social developments as a crisis factor, and the task of pedagogy as a fundamental assignment.

\section{Success Factor: Policy Leadership}

The most essential factor for success in Korea's ICT in education is the government's policy leadership. Policy leadership can be defined as uniting all actors whether the principal actor is the government, the state, or the society, in order to mobilize resources each actor holds. Policy leadership thereby aims to create all kinds of ecology, including policy environment, systems, and legal devices, which can be implemented to attain the set common goals and make the ecology work constantly through continuous cooperation, guidance, and supervision. In general, bottom-up approach and top-down approach are defined as an interactive model of policy strategies but in actual situation the two approaches are complementary. As such, for the success of bottom-up approach, it is necessary to facilitate top-down approach, and vice versa. Generally, policy leadership can be defined as using the top-down approach as a main strategy, but it cannot be successful without the emergence of leadership which can correspond to bottom-up approach. Leadership is actually defined by itself as the interactive process between the leader's and the follower's behaviors.

As the best example of policy leadership based on top-down approach during the ICT process in Korean education, the government took the strongest policy action and successfully gained the willing commitment from schools, teachers, parents, and students. The fact that Korea's successful ICT use in education for the past 15 years is the best example of policy leadership conversely means that the cause for the policy lag or gap which currently appears or is found is the issue of policy leadership. This will apply not only to Korea but also to all countries across the world.

A key element of policy leadership must be whether it targeted the very decisive trigger. In the 1990s immediately after the daybreak of the 21st digital and internet revolution, Korean society was united under one slogan: "Be the first country to achieve informatization, although late for industrialization". There was also a social consensus nationwide that this history of national ruin should not be repeated and based on this consensus, Koreans sufficiently shared the policy vision to become the first country to achieve informatization. The project for building the high-speed Internet began in 1995 together with the project for developing application software, and education inevitably lay in the core value of the projects. The ensuing policy options for the ICT use in schools included EDUNET (retrived from www.edunet.net) and ICT applied classrooms. EDUNET refers to an online teaching and learning platform including educational materials and various activities which can promote teachers' and student's participations through the high-speed Internet. EDUNET was open in 1996 and laid the groundwork for establishing the KERIS (Korea Education and Research Information Service, retrieved from www.keris.or.kr) on April 1, 1999, to become a successful model agency of ICT-driven educational system in the world. The EDUNET model has since become a facilitator of actively developing teaching-learning materials and establishing partnerships for sharing and distributing educational resources in the private and public sectors. The model has also become the prototype of free and safe contents on the recently booming cloud computing, Korea' ICT in education version 2, which was one of the key strategies for SEI (SMART Education Initiative) announced on June 29, 2011. 
Korea launched the project for ICT applied classroom, beginning with collecting coins from pay telephone booths in order to buy computers for schools. This policy model connecting every classroom on the Internet was a real success. A wide projection TV and Internet-connected PC respectively were installed at the classrooms in elementary and secondary schools nationwide. All teachers had to use ICT elements in more than 10 percent of class contents without fail, and computer literacy education was designated as a mandate. Classroom lessons led to homework and parents naturally began to use computers and the Internet at homes. Distribution of ADSL (Asymmetric digital subscriber line, is a type of DSL) spread this way, and as "ajumma"-Korea's married women caring for kids—-began to enjoy the Internet search and games while their children were gone to schools, they ushered in the age of the Internet Korea.

Policy leadership is not static, but it should spontaneously encounter with rapidly changing circumstances. Although Korea's ICT in education version 1 was a successful case in terms of the policy leadership based on top-down approach, this model could not last forever. SEI, Korea's ICT in education version 2, now calls for a new leadership. It may require strategies centering on bottom-up approach, not top-down approach. The policy lag that appears now is the reflection of this demand, which may not apply to Korea alone.

\section{Complex Factor: School Ecology for ICT Value Integration}

Korea's ICT in education developed differently for about 7.5 million students at more than 10,000 primary and secondary schools, and over three million at more than 400 colleges and universities. In fact, there were different causes for each problem. Many other things than the technology named ICT could not have done anything without the numerous corresponding factors that made it possible. Particularly, it was the just case for Korean schools, which are so much tighten-up and rigid that it is difficult to apply the new technology by welcoming newcomers into the ecological settings of the school, since the rigidity comes from the uniformity of Korean schools strictly controlled by the central law of education. It was an irony that such uniformity among the schools could be handled with the top-down approach policy leadership. This means that all schools can be successful or that all schools may fail. However, ecology has the ability to propagate. In other words, no actual ecology can be uniform and every school can protect itself from outside shock and invasion with its own principal of operation. This is the same with the fact that some schools were successful in the ICT process and others were not.

What were the conditions for successful schools in the use of the latest ICT in education? The answer can be found in the interaction between policy leadership and school ecology. In other words, the conditions for successful schools included each school's capabilities to exercise autonomous and active transformation of its uniform school ecosystem and to possess the essential elements for such transformation.

The first element to possess is the principal's leadership. Policy leadership is not a matter of the government and the state only. In the case of schools as well, it is the most essential issue whether the principal exercised leadership. We could find in common from many cases that it was a core element whether the school has a principal who has the will and competency to understand technological changes and connect ICT with education. This was the case with first successful schools and still holds true of schools today. This tells us that in connecting and accepting technology, the first thing to do is to nurture the competency of the school head.

The second element is the autonomy of teacher appointment and management, which is the source of principal's leadership. The greatest strong point and yet weak point as well is that all Korean teachers are government officials (except for private school teachers, although they are in the similar conditions) and that 
they work in rotation between schools. After all, it would be fair to say that schools are a part of grand national educational ecology rather than a single independent ecology. This is to say that the teacher community, a fundamental element of school ecology, does not share any vision and culture unique to their own school. Therefore, it is almost impossible for the school ecology to be at work and if it naturally works at all, it means that some unique teacher community and culture are created in the school. This phenomenon appears in common at schools which successfully achieved ICT in education.

A representative example showed that it was easier for private schools to accept ICT than public schools as the former could commonly maintain a relatively stable and unique culture for teaching profession than the latter. It was also found that secondary schools were relatively advantageous for the use of ICT as they had a greater proportion of private schools than primary schools. More successful cases were also found from schools, such as autonomous schools and specialized high schools, where autonomous rights to personnel management are given to principals, although limitedly in difficult situation. Schools were at the forefront of success if they had more or even one percentage of teachers who chose schools to work of their own accord, who were selected by principals, and who shared the vision to apply the value of ICT to change in school. The autonomy of personnel management of teachers was the first element to create such ecology of teaching profession.

The third element is school features. School features are a term that contains very diverse aspects and numerous elements, including the location of schools, composition of students, characteristics of local community, and history of schools. Except for the principal's leadership and culture for teaching job, the most important element of the features is the method of student composition. Even if an unfamiliar technological element like ICT is enforced by top-down policy approach to Korean schools as their selection of secondary high school students and method of recruitment are all restricted by the standardization policy, ICT can never be successful if students, its final school culture, cannot accept it. Above all, students can form a common school culture at schools of their own choice. A good example of these schools includes private schools and specialized or autonomous schools. In addition, an indispensable element is the feature of the local community where schools belong. An example for Korea's ICT process in education is schools at rural, mountainous, fishing, and remote areas. Because support for educational resources was concentrated on these schools that can be a socially vulnerable class, they were in relatively advantageous situations. Finally, difference was found in school levels. In other words, there were more policy success cases in primary schools than secondary schools. This completely reflects the special situation of Korean education, which is preoccupied with education for college entrance examination. Therefore, we can learn that the feature of curriculum by school level is a crucial ecological element in ICT models.

\section{Crisis Factor: The Gap Between Technology and Society}

Technology itself is something difficult and expensive. Teachers' reluctant and resistant culture comes from this inherent nature of technology. On the other hand, students who are relatively excellent with abilities to acquire technology accept technology more quickly than teachers, which is perceived as a threatening element to teacher group and traditional educational paradigm.

The trials of teachers in the period of Korea's ICT version 1 originated from this technological dilemma. Teachers were often denounced as a lazy and incompetent group of people who could not catch up with social and technological changes. In fact, they had to spend painful time secretly fighting "technology". Although they might have fallen behind the students they had to teach, they were still advanced in information technology compared to other adults. Spending painful hours, Korean teachers had to learn a lot of things. 
Korean teachers are still undergoing a difficult period of ICT in education when others are not. They have endured countless training sessions and social pressure but in fact this process was filled with moments of hardship. As it was supported by teachers' ICT competency, Korea could implement its phase I on the ICT in education version 1 with success. The teachers could equip themselves with the competency of ICT literacy thanks to at least three policy environments prepared for them.

First, the government implemented a powerful policy of using ICT in education so that teachers were almost forced to learn the technology for themselves in class. The government strongly demanded that they use ICT in any form for more than $10 \%$ of their lessons. Although teachers resisted to this demand at first, the government's strong demand directly contributed to raising their competencies. On the part of teachers, they could not carry out their lessons without attaining ICT literacy of their own accord. In addition, computer literacy had been designated as a required subject for a considerable period at primary schools and related certificates were required for the promotion of teachers.

Second, NEIS (National Education Information System), which was introduced on a full scale in 2004, played a crucial role in raising teachers' IT literacy. NEIS digitalized everything from student attendance management to academic performance management, college entrance and transfer management, and school budget management. Korean students could not do any school duties without going online on the computer, which naturally pressed them to raise their ICT literacy.

Third, the use of ICT in Korean society at large contributed to teachers' attaining ICT literacy in a natural way. Also, the use of ICT at schools brought forward the age of information technology in the whole society and made the use of ICT at homes and the work places as a natural phenomenon.

While teachers' ICT literacy slightly fell behind, students’ ICT literacy progressed at a far faster speed to outrun teachers. Students could immediately fix the problems with ICT devices that often occurred during class and called for more use of ICT devices in class. As the trend in ICT in education and society for the past two decades has brought in the era of the Net Generation, students no longer need to learn ICT literacy as a required subject at schools.

The SMART Education Initiative of 2011 was the version 2, which was adopted as a large-scale and comprehensive strategy to reform Korean education to meet the needs of the 21st century in name and reality in line with the development of ICT. However, teachers had to face another frustration and fears with ICT. Information technology, which had begun with offline computers, soon evolved to the Internet age and Korea is now evolving to a smart-technology society based on cloud computing and mobile devices. Almost all Koreans came to communicate with smart-phones and as a result we are in a situation where this communication technology should be introduced to school education on a large scale.

Also, this undeniable policy element eventually appears again in technological gap. From devices, OS (operating system), web standards, network standards to risk factors of electronic waves, and the Internet and game addiction, social changes arising from information technology are too overwhelming challenges for teachers to deal with. They are felt like a fearsome disaster to teachers who are familiar with traditional education based on subject knowledge. ICT is still no easy technology like TV or cars, which they have only to turn on the set or the engine. The prices of ICT devices are not low enough for everyone to get access to. As such, the gap between technological development and social adaptation has been widening rather than narrowing. Global ICT businesses and national policy-makers should earnestly think over how to resolve this technological gap. This is the task Korea's ICT process left to them. 


\section{Fundamental Assignment: Pedagogy and ICT}

Although five millennia have passed since the invention of alphabetic symbols and five centuries, since the invention of printing, a great number of children across the world still cannot overcome illiteracy. Although it has progressed for over five millennia, the pedagogy is still concentrated on teaching basic subjects such as reading, writing and arithmetic. With the development of information technology and advance into an age of the 21st century knowledge-based economy, conventional schools are criticized for teaching old-fashioned knowledge of the 19th century and earlier when they should instead teach students to nurture their competencies of the 21st century. However, on the part of schools and teachers, there are only jargons in technology, which they cannot understand. Korea's ICT history in education shows all kinds of positive and negative aspects of traditional pedagogy's response to ICT, which emerged as a new civilization code. When pedagogy is defined as "the activities of educating or instructing", Korean lessons tell us what difference should be taken into consideration between this traditional pedagogy and a new pedagogy (Chun, 2013).

Traditional pedagogy starts with overcoming the basic literacy of 3Rs. The goal of the curriculum is to equip students with the abilities of making a living in the world by this literacy. With this goal, all subjects at schools pursue to foster the ultimate abilities of this basic literacy. But, now entering information and knowledge-based society, this concept of literacy has been changing. Reading and writing have already become an easy job, at least to Korean children, though, not to all children across the world. Even Einstein's theory of relativity has become knowledge that is accessible on the Internet even without taking the trouble to go to school. Students' demand for a new pedagogy has now become a global declaration when discussing education of the 21st century. However, schools still teach these traditional skills because there are no other subjects to teach yet. Also, believing that competency is raised when literacy is taught, traditional pedagogy does not address how to teach such a new competency. Moreover, if the ultimate goal of education is communication competency, the Net Generation was already born equipped with ICT literacy and competency. From the viewpoint of ICT literacy, students are better than teachers. Now is the time for a new pedagogy to redefine this basic literacy. In this sense, the traditional pedagogy should now be changed as follows:

First, it should dispose of the concept of teaching the basic literacy and shift toward experiencing the 21st-century competencies. Schools should resolve certain problems together with students rather than teaching something to students. Whether kindergarten or college level, they should not set a hierarchy of subject knowledge by level but instead set a hierarchy of problem-solving tasks by developmental stage of students. For instance, they should offer tasks of learning basic habits at the kindergarten level, and tasks of getting a job and marriage at the college level.

Second, it should drastically throw away the existing knowledge of professional pedagogy. Since the implementation of SMART Education Initiative, the gaps in technological understanding and competency between field teachers, schools, professions, and students have noticeably widened. This means that any development cannot be attempted with a certain standard and uniform pedagogy. Therefore, the pedagogy should shift toward opening an age of creativity and empathy through collaboration and sharing on the Web 2.0 space of the ideas of all people involved in educational activity, businesses, adults and children, policy-makers and the general public.

Third, investment in easier and low-priced smart-technology should be made and technology should be first distributed to the less privileged. Smart-technology is still difficult and expensive. Global ICT businesses, 
international organizations and general citizens should create a world where all people can share easier and less expensive smart-technology. What must be included in these technological requirements is the space for sharing free and safe educational contents. Building a network of global brain where everyone can share the knowledge and technology of mankind fettered by copyrights and technology should become the most essential task. Many say that we do not need to go to school as we can get useful information on the Internet space. However, it is still difficult to search necessary data or there is no such information. Even if it is there on the Internet, it is too expensive to gain access to the information.

\section{Conclusions}

Education for all has been a long-cherished wish of mankind. It is, in fact, a variation of literacy for all. However, we have not achieved any of the two wishes yet. The task of traditional pedagogy, which has dreamed to accomplish for more than five thousand years and yet uncompleted, is passed over to the task of a new pedagogy. Rather than EFA (Education For All) goals pursued by international organization, CFA (Connect For All) goals might be needed in modern society. We need to help all children across the world meet online with their own words, expressions, songs and gestures. If they meet with each other, they will build their own world as they dream of. Our experience from Korea's ICT version 1 and visions for its ICT version 2 SMART education are that rather than providing books and teachers and building schools, it can be a less expensive and more effective way to make smart-pads, the Internet, and contents cloud computing for children.

\section{References}

Chun, S. (2013). Education and freedom. Seoul: Hakjusa.

Chun, S., Kim, J., Kye, B., Jung, S., \& Jung, K. (2013). Smart education revolution. Seoul: 21st Books.

Chun, S., Kim, J., Kim, Y., Lee, O., Choi, S., Park, S., Lee, G., Lee, S., \& Lee, S. (2013). Study of development of smart education policy performance indicators. KERIS.

Council on Informatization Strategies \& Ministry of Education, Science and Technology. (2011). Smart education strategies.

Intel. (2011). Guide to monitoring e learning programs: Intel education transformation research standard research design and toolkit. Intel Corporation.

Korea Education and Research Information Service. (2012). Formation of plans for smart education model development and implementation. KERIS.

Kye, B., Lee, E., Kim, J., Park, S., \& Lee, G. (2013). Survey report of technology-based school conditions. KERIS.

Lee, J., Gu, Y., Shin, G., Kim, D., Kye, B., \& Jung, S. (2012). Study of program development for operating creative and problem-solving smart education. KERIS.

Ministry of Education, Science and Technology. (2011). Implementation plans for SMART education strategies.

Ministry of Education \& Korea Education and Research Information Service. (2013). White paper of ICT in education 2013.

Park, S. (2007). Direction and challenges for improving curriculums of teacher training. The Journal of Korea Teacher Education Research, 24(2), 143-173.

Song, M., Rim, H., Choi, H., Park, H., \& Son, S. (2013). OECD programme for international students assessment: Analyzing PISA 2012 results. Korea Institute for Curriculum and Evaluation.

Yi, S. (1996). Technology education in Korea: Curriculum and challenges. The Journal of Technology Studies, 23(2), 42-49. 